Helium Pot System for Maintaining Sample Temperature after Cryocooler Deactivation

B. J. Haid

February 3, 2005

2005 Cryogenic Engineering Conference and International Cryogenic Materials Conference Keystone, CO, United States August 29, 2005 through September 2, 2005 
This document was prepared as an account of work sponsored by an agency of the United States Government. Neither the United States Government nor the University of California nor any of their employees, makes any warranty, express or implied, or assumes any legal liability or responsibility for the accuracy, completeness, or usefulness of any information, apparatus, product, or process disclosed, or represents that its use would not infringe privately owned rights. Reference herein to any specific commercial product, process, or service by trade name, trademark, manufacturer, or otherwise, does not necessarily constitute or imply its endorsement, recommendation, or favoring by the United States Government or the University of California. The views and opinions of authors expressed herein do not necessarily state or reflect those of the United States Government or the University of California, and shall not be used for advertising or product endorsement purposes. 


\title{
Helium Pot System for Maintaining Sample Temperature after Cryocooler Deactivation
}

\author{
Benjamin J. Haid
}

A system for maintaining a sample at a constant temperature below $10 \mathrm{~K}$ after deactivating the cooling source is demonstrated. In this system, the cooling source is a GM cryocooler that is joined with the sample through an adaptor that consists of a helium pot and a resistive medium. Upon deactivating the cryocooler, the power applied to a heater located on the sample side of the resistive medium is decreased gradually to maintain an appropriate temperature rise across the resistive medium as the helium pot warms. The temperature is held constant in this manner without the use of solid or liquid cryogens and without mechanically disconnecting the sample from the cooler.

Shutting off the cryocooler significantly reduces sample motion that results from vibration and expansion/contraction of the cold head housing. The reduction in motion permits certain processes that are very sensitive to sample position stability, but are not performed throughout the duration that the sample is at low-temperature.

An apparatus was constructed to demonstrate this technique using a 4K GM cryocooler. Experimental and theoretical predictions indicate that when the helium pot is pressurized to the working pressure of the cryocooler's helium supply, a sample with continuous heat dissipation of several-hundred milliwatts can be maintained at $7 \mathrm{~K}$ for several minutes when using an extension that increases the cold head length by less than $50 \%$.

Lawrence Livermore National Laboratory, PO Box 808, Livermore, CA 94551-0808

This work is supported by DOE Contract No. DE-AC03-01SF22260.

This work was performed under the auspices of the U. S. Department of Energy by University of California, Lawrence Livermore National Laboratory under contract No. W-7405-Eng-48. 